\title{
Inquest verdict on Met. Office failure to predict storms
}

\section{London}

THE inquest into the failure of the British Meteorological Office to predict the severity of the storm that killed 19 people on 15-16 October last year has not identified a culprit - unless it is the British Treasury. The reports of two separate inquiries into the affair were published by the Ministry of Defence last week.

The independent report by Sir Peter Swinnerton-Dyer (Chairman of the University Grants Committee) and Professor Robert Pearce (University of Reading), commissioned by the ministry after the Met. Office had mounted an internal inquiry, concluded:

- British weather forecasters are inadequately trained.

- Senior forecasters have anomalously low status within the Met. Office hierarchy.

- Cuts in government support of the Met. Office have resulted in minimum staffing levels and inadequate computer power.

The report of the internal inquiry set up by Dr John Houghton, director-general of the Met. Office, says that paucity of data coverage gave an inadequate description of the storm and the atmospheric structure in its vicinity. This report calls for an improved observational network, further development of the forecasting models used and a review of procedures for handling warnings of severe weather.

The government says it accepts the recommendations of both reports, but that they will have to be carried out within the Met. Office's budget of some $£ 105$ million.

Swinnerton-Dyer and Pearce conclude that there were two reasons for the inadequate public warning last October. First, the computer forecasts available on 15 October disagreed, with the result that all forecasts underestimated the strength of the storm and, second, the duty forecasters

\section{IMAGE UNAVAILABLE FOR COPYRIGHT REASONS}

Satellite picture of the storm at 08.19 GMT on 16 October 1987.

\section{UK environmental research remains against the ropes}

\section{London}

BRITAIN's contribution to environmental research of national and global importance is being eroded by starvation of public money. So much is clear from the corporate plan of the Natural Environment Research Council (NERC), published this week.

In real terms, NERC income from the science budget, excluding money for the British Antarctic Survey, is expected to decline by $£ 2$ million by $1990-91$ to around £61 million. Income from commissioned research has failed to meet NERC's expectations and has forced the council to rethink its priorities. Last year's corporate plan had expected income from commissioned research to be at around $£ 34$ million by $1988-89$. The revised figure is nearer to $£ 29$ million. NERC has already announced that it may have to introduce compulsory redundancies for the first time as part of a series of cost-cutting measures.

NERC says that to meet its defined strategic objectives it would require $£ 150$ million by 1989-90. Current prospects fall short of this by $£ 22$ million, with the gap increasing to $£ 35$ million by 1993-94.
NERC's revised plans will result in a significant reduction in its support for university research. The council had originally intended to increase expenditure in universities by $£ 1.9$ million in $1988-89$ from its existing level of $£ 13.4$ million. Now it has been forced to cut $£ 0.7$ million.

From a total staff of 3,263 at the beginning of 1983 , NERC employed 2,733 by the end of 1987 , a reduction of 16 per cent. The 1987-88 forecast of shedding 100 posts was not achieved, largely because of a drop in the numbers of people volunteering to leave prematurely. The council's present plan identifies the following programmes that will be foregone or restricted if it does not receive the necessary annual income.

- $£ 10$ million for geological surveying.

- $£ 5$ million for interdisciplinary research centres. Specific proposals have been made for centres, including population biology, deep crystal studies and environmental microbiology.

- $£ 7$ million for strategic programmes in agriculture, environment, the North Sea project and the biogeochemical ocean flux study. failed to recognize a situation in which computer models were likely to underestimate the strength of the winds. But this report exonerates the duty forecasters, saying that there was "considerable unluckiness in the circumstances".

Last October's storm seems to have been a consequence of unusual meteorological conditions. The report links hurricane Floyd, which had developed in the Caribbean by 11 October, and the hurricane-force winds reaching south-east England on the night of 15 October.

The British storm was an intense midlatitude cyclone, the energy of which derives from the contrast between warm air from subtropical regions and cold air from polar regions. The Earth's rotation means that the warm air moves upwards and ahead of the storm towards the pole and the cold air sinks towards the Equator behind it. Belts of strong upper and lowlevel winds (low-level jet) were associated with these regions of ascent and descent.

The gusts of hurricane force at the surface were the consequence of turbulent eddies in the lower atmosphere bringing air down from near the low-level jet. An upper-level jet streak, a region of 150 m.p.h. winds at a height of about $10 \mathrm{~km}$, probably originating from hurricane Floyd, arrived off the Bay of Biscay and was a primary factor in causing the rapid development and deepening of the depression.

The report acknowledges that the observational network is poor to the southwest of Britain, where the storm originated, when computer models can give inadequate forecasts. It says that on this occasion the forecasters "largely accepted" the predictions of the model and that they "were either not aware of or underestimated the importance of the low-level jet".

The Met. Office has two forecasting models of low and high resolution ('coarsemesh' and 'fine-mesh'). As reported earlier in Nature $(329,750 ; 1987)$, the forecasters were faced with conflicting forecasts. Although the coarse-mesh model is regarded as inferior, the fact that it is run later than the fine-mesh model meant that on 15 October it was crucially based on more up-to-date observations.

On the performance of the French meteorological services in forecasting the storm, the independent report says that the French forecasters displayed a "better appreciation of the nature of the phenomenon they were dealing with", perhaps because of the deeper training they receive. Also, the computer used by the Met. Office is less powerful than the French, with the result that the French service can run a fine-mesh model of twice the resolution. This is an "unnecessary handicap" says the report, and the authors are "relieved" that the Met. Office is to have a new ETA 10 supercomputer soon, even if the cost will have to be met through internal economies.
Philippa Lloyd 